Estudios sobre el Mensaje Periodístico

ISSN-e: 1988-2696

http://dx.doi.org/10.5209/ESMP.55589

\title{
Crónica latinoamericana. ¿Existe un Boom de la no ficción?
}

Andrés Alexander Puerta Molina ${ }^{1}$

Recibido: 28 de junio de 2016 / Aceptado: 24 de noviembre de 2016

Resumen. El objetivo de este artículo es determinar por qué se dice que hay un nuevo Boom de la literatura latinoamericana, esta vez en la no ficción, a través del género de la crónica. Se hace con múltiples entrevistas a cronistas, editores y estudiosos y con un análisis de las razones que han permitido un auge de este género.

Palabras clave: Crónica; Latinoamérica; boom literario; Fundación Nuevo Periodismo Iberoamericano; Internet.

\section{[en] Latin American Chronicle. Is there a Boom in nonfiction literature now?}

Abstract. The objective of this article is to determine why it is said that there is a new Boom of Latin American literature, this time in the nonfiction, through the genre of chronic. It is made with multiple interviews with reporters, editors and researchers and analysis the reasons that there is a boom in this genre. Keywords: Chronic; Latin America; literary boom; Fundación Nuevo Periodismo Iberoamericano; Internet.

Sumario. 1. Introducción. 2. Metodología. 3. ¿Existe un nuevo Boom de la literatura latinoamericana y está en la no ficción?. 4. Conclusiones. 5. Referencias bibliográficas. 6. Entrevistas.

Cómo citar: Puerta Molina, Andrés Alexander (2017): “Crónica latinoamericana ¿Existe un Boom de la no ficción?", en Estudios sobre el Mensaje Periodístico 23 (1), 165-178.

\section{Introducción}

Esta investigación se enfocó en indagar acerca de la crónica, un género que busca atrapar el tiempo para dejar una huella del paso del hombre por la tierra. Como siempre fracasa en ese intento de aprehender algo tan etéreo como lo temporal, tiene que volver a empezar. La crónica, a diferencia de las noticias, no muere con el atardecer, tiene una forma particular de envejecer que, como en el caso de los buenos vinos, toma cuerpo con el paso del tiempo.

Esa vitalidad le permite una estrecha relación con la literatura. La crónica reclama un lugar dentro de los géneros literarios, no tiene nada que envidiarle a los cuentos más originales. En las mejores crónicas los autores indagan acerca de lo esencial

$1 \quad$ Universidad de Medellín (Colombia).

E-mail: andrespuerta@udem.edu.co 
de la condición humana, se la juegan en la creación de una obra estética. La única diferencia es que no inventan nada, sus personajes existen o existieron y eso los hace más cercanos a los lectores, que pueden identificarse con sus historias. Ese lugar que reclama el buen periodismo ya está siendo reconocido incluso por la crítica, que antes miraba a estas formas de periodismo con desdén. Así lo demuestra el premio Nobel otorgado a la bielorrusa Svetlana Aleixevish, una periodista que logró captar difíciles realidades y contarlas con la belleza de poetas y novelistas.

La crónica ha sido un género practicado con éxito y con constancia en América Latina, ha recibido influencias de la literatura pero también ha innovado en la literatura. Últimamente se habla de un Boom de la literatura latinoamericana a través de la crónica. Hay una brillante generación de cronistas que ha despertado interés en América y Europa. La crónica latinoamericana se ha ganado un espacio que, salvadas las proporciones, ha hecho que se hable de un nuevo Boom, como el fenómeno que catapultó a la fama a García Márquez, Vargas Llosa y los demás. Este artículo indaga en las razones por las que se habla de un nuevo Boom.

\section{Metodología}

El proceso de la investigación comprendió la lectura interpretativa desde una perspectiva semiótica de una serie de crónicas propuestas en un amplio corpus, los textos que indagan acerca de las relaciones entre el periodismo y la literatura, así como los libros de algunos cronistas latinoamericanos. Estos textos fueron utilizados como fuentes primarias.

Para analizar el presente de la crónica latinoamericana se definieron unos temas que funcionan como un localizador: la labor de los cronistas, de los estudiosos, de los editores, de los talleristas, de las editoriales, de la Fundación Nuevo Periodismo, de internet como medio de difusión, de los premios, de los antologistas e incluso de la Historia de la crónica en los diferentes países. Este panorama amplio que analiza diferentes factores y actores permite tener una visión completa de lo que está pasando. Fue una de las partes más complejas, pero también más profundas del trabajo porque implicó ir a los países en los que habita la crónica y buscar la voz de los diferentes protagonistas. Hubo una labor rigurosa de investigación y de realización y transcripción de entrevistas a investigadores y a cronistas que con su trabajo de periodistas comprometidos con una absoluta dignidad literaria están impulsando un género para comprender la realidad social. La realización de estas entrevistas es la aportación original a este trabajo.

\section{3. ¿Existe un nuevo Boom de la literatura latinoamericana y está en la no ficción?}

E1 Boom de la literatura latinoamericana fue un movimiento en el que coincidieron grandes escritores entre 1960-1970 y que lograron un nivel nunca visto. Gustavo Faverón Patriau, en su artículo Breve historia de la explosión más larga del mundo resume esta historia:

En 1962, Mario Vargas Llosa ganó el premio Biblioteca Breve con su primera novela, que hasta entonces se había llamado La morada del héroe pero que en 
adelante sería conocida como La ciudad y los perros. Ese mismo año, Gabriel García Márquez publicó El coronel no tiene quién le escriba, y Carlos Fuentes, La muerte de Artemio Cruz. Solo mediaron unos meses entre la aparición de todos esos libros y la más popular de las novelas argentinas, Rayuela, de Julio Cortázar. La confluencia de sus obras hizo que los cuatro autores fueran percibidos como miembros de una misma generación. Se trataba, por supuesto, de una licencia histórica: Vargas Llosa apenas pasaba los veinticinco años; Cortázar casi le doblaba la edad; Fuentes y García Márquez, nacidos en 1928 y 1927, eran coetáneos entre sí, pero no de los otros: una década mayores que Vargas Llosa, una década y media menores que Cortázar. En 1966, Vargas Llosa publicó La casa verde, y Cortázar, Todos los fuegos el fuego, con algunos de sus relatos más memorables: «La autopista del sur», "La salud de los enfermos», "La isla al mediodía». En 1967, Vargas Llosa dio a la imprenta Los cachorros, y García Márquez, Cien años de soledad. En cinco años, la ficción latinoamericana había pasado, particularmente ante los ojos de los lectores europeos y norteamericanos, de la parcial anonimia al más relumbrante estrellato (Faverón, 2013: s.p.)

En el mismo artículo, Faverón afirma que el periodista chileno Luis Harrs fue el primero que utilizó la palabra Boom para designar a una generación, que Carlos Fuentes denominó como integrantes de la nueva novela latinoamericana:

Lo que el nombre Boom sugiere, con su sonoridad de onomatopeya y su bramido de cañonazo repentino, es que hubo un momento en la historia de la literatura latinoamericana cuando súbitamente apareció algo que era nuevo, insólito, imprevisto y asombroso, algo que no solo no se originaba en la historia literaria previa, sino que belicosamente cortaba con ella: Boom es un nombre como un balazo parricida, un nombre rebelde, rotundo (Faverón, 2013: s.p.)

Para muchos, la literatura latinoamericana fue una antes y otra después del Boom, tanto que siempre se ha buscado una generación comparable en la literatura latinoamericana o se ha intentado encontrar a un grupo que recoja la posta y vuelva a poner en la órbita planetaria a las letras del continente:

cuando apareció el Boom originario estaba completamente asociado a la ficción, a la narrativa, en particular a la novela y desde entonces se ha creado una especie de síndrome de que debería llegar una segunda oleada del Boom o que debería haber un recambio en los autores primeros de ese Boom y fue pasando el tiempo e iba una decepción tras otra. Creo que la entusiasta recepción que ha habido con Bolaño tiene que ver con esto, con que por fin la expectativa que se había tenido durante tantos años se cumplía (Jursich, 2013: entrevista).

Los más entusiastas dicen que el nuevo Boom ha llegado ahora en forma de crónica, para ellos la literatura de no ficción es la que mejor cuenta los destinos de Latinoamérica. Esto fue lo que planteó, por ejemplo, el poeta y estudioso colombiano Darío Jaramillo Agudelo, en el prólogo de la Antología de la crónica 
latinoamericana actual, y es algo similar a lo que piensa la cronista venezolana Sandra Lafuente:

La reciente cumbre [...] para la entrega del premio García Márquez confirma que el presente de la crónica latinoamericana es mejor [...] la crónica está siendo cada vez más necesaria para registrar e interpretar la nueva realidad —o la vieja, la de la estructural violencia, la de la pobreza y el hambre más grande o más residual, que tiene costados diferentes: está la crónica latinoamericana pasando por el filtro de un mayor rigor en la reportería [...] el periodismo se ha fortalecido, aunque pareciera que viviera su hora más negra (Lafuente, 2014: entrevista).

La crónica se ha convertido en la manera en que los cronistas retratan la realidad en la que viven, desde la crudeza de la violencia, hasta la restricción de las libertades. En los momentos de mayor censura es cuando ha sido necesario ser más creativo para contar historias, en los momentos en los que hay más violencia, es cuando ha sido más imperioso contar lo que está sucediendo. Lo que ocurre actualmente con la crónica entusiasma, pero los involucrados en el mundo de la crónica piden ser cautelosos, como lo expresa el editor colombiano Mario Jursich:

Yo creo que sí hay un segundo Boom, pero ya no está en la narrativa sino en un sitio en el que nadie estaba mirando y en este caso es el periodismo narrativo, eso que a falta de un mejor título llamamos crónica. El primer Boom ya sabemos todo lo que pasó, tuvo un éxito planetario, dos autores de esos que terminaron ganando el premio Nobel de literatura; pero con la crónica periodística está pasando una cuestión distinta. A mí no me cabe duda sobre su importancia en términos narrativos. Sí tengo es un interrogante respecto a qué tan popular es el género, hay poca gente practicándolo [...] y no veo a tanta gente leyéndolo [...] y eso llama la atención porque libros de este estilo en países como Estados Unidos a menudo han sido Best Sellers (Jursich, 2013: entrevista).

Últimamente se han publicado antologías en España, en Alemania, en Austria y hasta en Inglaterra. En España e Italia se han publicado artículos que indagan acerca de lo que sucede con la crónica latinoamericana. Cada vez hay más talleres de crónicas, revistas que publican trabajos y premios que buscan reconocer a los talentos con trayectoria y descubrir nuevos narradores, hay tesis y estudios que se ocupan del tema. Eso sí, son pocos los cronistas que pueden vivir de su oficio, aún los libros de crónicas no tienen ni siquiera una distribución continental, algunos hablan de un Boom de la crónica latinoamericana, para otros es simplemente el embeleso de un grupo reducido. Para el periodista cultural Leonardo Tarifeño el tema no es una cuestión de nomenclatura y va más allá:

más allá de los calificativos rimbombantes desempolvados para la ocasión, hay gran cantidad de escritores cuyas obras enriquecen el panorama de la literatura contemporánea. La no ficción periodística en lengua española ya alcanzó la mayoría de edad. No necesita comparaciones, ni eslóganes, ni defensas apasionadas. 
Se justifica por sí misma y cualquier lector curioso está invitado a descubrirla (Tarifeño, 2012: s.p.)

Las opiniones son muy diversas y se dispersan a lo largo del continente. En esta investigación se intentó tener un panorama global y por eso se hicieron varios viajes en los que se entrevistó a diversos protagonistas para indagar acerca de qué está sucediendo con el género y qué piensan acerca de si hay un Boom de la crónica latinoamericana. El periodista ecuatoriano José María León Cabrera, un innovador en el tema de las revistas digitales con Gkill City, también cree que el tema va más allá de las etiquetas:

Efectivamente se está produciendo más y hay más llegando y si eso es un Boom qué chévere. Lo que sí creo es que los latinoamericanos tenemos esa costumbre de la grandilocuencia, somos proclives a estas etiquetas pomposas, que ya existieron, que han existido siempre. Lo que sí estoy consciente es que es un momento muy duro para los medios, pero ese momento tan duro sucede, al mismo tiempo, como un gran momento para los cronistas y creo que eso dice mucho. Lo que creo más que un Boom, lo que hay es un gran momento para el periodismo, te diría en el mundo; pero en Latinoamérica se vive especialmente (León, 2013: entrevista).

El hecho de que haya un mayor interés, sobre todo en Europa, hace que exista un optimismo con respecto a este género periodístico. Hay autores que valoran un momento en el que se estudia, se discute y se publica más crónica latinoamericana, como es el caso del editor colombiano Camilo Jiménez:

se habla de ella, se organizan encuentros, concursos y conversatorios; se publican antologías, se escriben tesis y artículos académicos y de los otros. Hay un interés manifiesto hacia el género como hecho cultural. Sin embargo, sigue estando un poco relegada de los medios impresos, y prácticamente ha desaparecido de los diarios, el medio que la acogió desde su nacimiento hacia la segunda mitad del siglo XIX (Jiménez, 2014: entrevista)

Hay algunos protagonistas que son mucho más cautos y miran con distancia lo que fue el Boom y lo que sucede hoy en día con la crónica latinoamericana. Para el Venezolano Boris Muñoz hay unas condiciones más favorables, pero el fenómeno de la crónica aún no es un éxito comercial, como sí lo fue el Boom de la literatura:

se escriben crónicas en muchos países, se leen crónicas, hay libros de crónicas y estos libros tienen público que se compran la edición, es un fenómeno que no es solo marketing sino también un fenómeno de producción que está ligado al periodismo de calidad. Eso sí son solo un puñado de cronistas los que pueden vivir de su trabajo y un puñado es un puñado, no más de 10 o 15 (Muñoz, 2013: entrevista)

Para los cronistas son claras las dificultades, existen pocos medios, se paga mal, es complejo vivir del oficio, las iniciativas tienen mucho que ver con intereses in- 
dividuales, con el deseo de contar historias. Esta investigación también se centra en otros protagonistas dentro del panorama de la crónica, para editores y estudiosos son claras las virtudes y también las falencias, como las que indica Leila Guerriero en el texto La verdad y el estilo, cuando cita a Guillermo Osorno:

Pero ¿sabes para mí qué sería el signo inequívoco del Boom? Sentarme con las patas encima de mi escritorio a esperar a que lleguen a mi cuenta de correo textos arrebatadores, después de que los autores estuvieron con toda calma investigando sus temas, y poder pagar lo justo por esos textos. Y no. Pero sí veo una confluencia de voluntades por hacer periodismo narrativo (Guerriero, 2012: s.p.).

La crónica no es masiva, nunca lo ha sido y tal vez no pretenda serlo. Afrontar un género que supone un gran esfuerzo económico e intelectual y que no recibe una contraprestación económica equivalente es una actividad profesional muy vocacional. Existe la idea de que ser cronista da un cierto prestigio. Así lo piensa el escritor mexicano Juan Villoro, uno de los principales referentes de la crónica latinoamericana actual:

Creo que el prestigio de la crónica es mucho mayor a la posibilidad de ejercerla. Hoy es mucho más fácil hacer un seminario de crónica, participar en un premio de crónica, una antología de crónicas, que publicar crónicas en los periódicos. Hay algunos espacios pero no son suficientes. Tampoco hay una costumbre de que se asignen crónicas regularmente. Los grandes cronistas, entre ellos Caparrós, tienen que financiar ellos mismos sus proyectos. Si tú ves, la mayoría de libros recientes que él ha escrito han surgido de trabajos que ha hecho para las Naciones Unidas y que luego ha convertido en libros. Yo creo que hay muy buenos cronistas en lo individual, pero no es una tendencia tan colectiva como pudiera pensarse (Entrevista a Jun Villoro, en: Benavidez, 2014).

Martín Caparrós ha llegado a afirmar lo siguiente respecto al boom de la crónica: "es más probable que tu editor te pida 2.000 caracteres sobre el buen momento de la crónica a que te pida una crónica de 2.000 caracteres" (Caparrós, citado por Jiménez, 2014: entrevista). Y autores como Rodrigo Villarreal en El gran retrato de nuestro tiempo piensan que este fenómeno ha sido excluyente:

Hoy día el llamado Boom es un tanto artificioso y con fines comerciales, más un fenómeno de librería que periodístico que deja de lado a numerosos periodistas que han practicado ese género desde hace muchos años. Creo que incluso se han convertido en una especie de cofradía, la de los periodistas narrativos, que no son todos ni los mejores. Se distinguen, sobre todo, por una postura que se quiere crítica hacia la violencia del Estado y de los grupos criminales, por la descripción de los graves problemas sociales de los países de América Latina, pero también por su simpatía tácita por regímenes socialistas y autoritarios. 
Han caído en una especie de club de abrazos mutuos en el que cada uno es más aguerrido que el otro. Otra cosa: la mayoría venera de manera desmedida a Kapuscinski, García Márquez, Monsiváis, Villoro y otros (Villarreal, 2013: p.19).

Se habla de un pequeño grupo que domina el panorama. Hay varios estudiosos, cronistas y editores que juzgan este fenómeno como una cofradía de unos pocos. La idea contraria la tiene Jon Lee Anderson, citado por Jorge Tirzo en ¿Nueva crónica latinoamericana?:

No sé quién lo dijo primero, pero yo lo dije sin saber que otro lo había dicho. No es que yo sea un abanderado tratando de vender un producto. Yo sí lo comparo con el Boom de la ficción. Estamos frente a un nuevo Boom latinoamericano. Lo digo porque yo no sólo me paso la vida aquí. Viajo por América del Norte; Europa, donde vivo; África; Medio Oriente, ando en muchas partes del mundo todo el tiempo y no veo un Boom parecido (Lee Anderson en Tirzo, 2013: p.13)

Este argumento de Jon Lee Anderson se ha demostrado cuando se han presentado los dos encuentros de Nuevos Cronistas de Indias, una iniciativa de la Fundación Nuevo Periodismo y que se coronaba con la entrega anual del premio García Márquez de Periodismo. Estos encuentros congregaron en Medellín, Colombia, a algunos de los mejores cronistas del continente. Hay quienes tienen una visión muy optimista, como en el caso de Carolina Ethel, quien en el artículo La invención de la realidad, escrito para el periódico El País de España, afirma:

América Latina ha dejado de ser un continente inventado por la literatura para transformarse en un continente redescubierto por los narradores. Un grupo de periodistas se ha situado en la vanguardia literaria con sus ganas de "contar cosas que no fueron soñadas en una noche apacible, sino que fueron vistas en el día anterior y de la vigilia, cosas que están pasando" (Ethel, 2008: s.p.).

Esta visión de Carolina Ethel la comparten varios autores y ha generado una fuerte polémica: algunos dicen que la mejor literatura, la más interesante, la más dinámica que se hace actualmente en el continente la escriben los cronistas, como sucedió con el Nuevo Periodismo estadounidense. Hay quienes reivindican la supremacía literaria de la no ficción, aun asumiendo que en ambos casos, en el de Norteamérica y el de Latinoamérica, se está produciendo literatura de ficción con una alta calidad. La argentina Leila Guerriero piensa que la situación constantemente cambiante de América Latina ha ayudado al desarrollo de la crónica latinoamericana y le ha dado una impronta única:

En América Latina vivimos esta dinámica de crisis desde que nacemos. Cada cinco o diez años hay una crisis en la que el Gobierno o el banco se quedan con tu dinero, o tu dinero no vale nada. Hay que tener un plan A y diecisiete planes B. Uno crece en esa dinámica en todos los ámbitos: laboral, privado [...] Vives con precaución y a la vez con un espíritu kamikaze, porque si eres precavido todo el tiempo terminas no haciendo nada. Ese espíritu ha ayudado a que pase todo esto 
que se dice que pasa con el periodismo narrativo (Entrevista a Leila Guerriero, en Lobo: 2014).

Leila Guerriero es una de las autoras que más ha reflexionado acerca de las características de la crónica y también es una de las autoras más reconocidas. Se ha convertido en una especie de estrella de rock cuyos groupies se reúnen cada vez que da una conferencia. Ella tiene clara la diferencia entre el Boom de la literatura latinoamericana y lo que pasa actualmente con la crónica:

Si a una persona normal le dices: Mario Vargas Llosa, García Márquez o Carlos Fuentes, reconocerá el nombre, recordará la cara, quizá hasta se ha leído alguna novela. Si le dices «crónica» al dueño de una tienda, al chico de la recepción del hotel o a un ingeniero, los pones en un aprieto [...] los periodistas narrativos estamos mejor que hace 15 años. Por lo menos se habla más del tema. Pero no creo que sea un Boom, ni que sea comparable. ¿Cuántos miles de ejemplares vendían estas personas? Eso fue un Boom. El Boom sería que mañana, como editora de Gatopar$d o$, me sentara con las piernas sobre el escritorio y dijera «Lluevan veinte crónicas fantásticas para la revista del próximo número». (Entrevista a Leila Guerriero, en Lobo: 2014).

El reconocimiento y la solvencia económica son dos hechos fundamentales para plantear una diferencia entre el Boom de la literatura latinoamericana y el auge que ahora tiene la crónica. Los autores del boom literario tuvieron un reconocimiento mundial. Los cronistas de este 1 boom periodístico se distancian enormemente de tal reconocimiento.

Una de las instituciones que más ha ayudado para el desarrollo de la crónica es la Fundación Nuevo Periodismo Iberoamericano, dirigida por Jaime Abello Banfi, uno de los defensores de los cronistas como autores y que piensa que la comparación con el Boom original es perfectamente válida:

sí hay un cierto Boom de prestigio, inclusive de un prestigio para algunos autores y también para el género o por lo menos la práctica de la crónica. Creo que para los jóvenes estudiantes hoy en día ya es un referente en muchas partes de América latina la idea de ser cronistas, es una de las perspectivas más interesantes del periodismo, porque básicamente nos remite a una idea que me parece central que es la idea de periodismo de autor. Estoy convencido que el nombre de autor es fundamental para entender todo este Boom, que en alguna manera lo hay y tiene que ver con un hecho que es la desestructuración del antiguo sistema del periodismo basado en los medios (Abello, 2013: entrevista).

Leila Guerriero y Alberto Salcedo Ramos han adquirido celebridad en América Latina y los dos, además, son reconocidos en España: Guerriero tiene una columna en El País y Salcedo en El Mundo, respectivamente. El editor chileno Patricio Fernández apoya la idea de que la Fundación Nuevo Periodismo ha sido fundamental para dignificar el trabajo del cronista: 
Antes hasta hace muy poco atrás escribir un reportaje así fuera con todo el esfuerzo maestro con todo el cuidado del lenguaje por la precisión y por la literatura era visto como algo menor, hoy en día no. En eso hay que decir que la Fundación Nuevo Periodismo tiene una responsabilidad importante porque ha ayudado a dignificar eso ha sido un lugar de encuentro y efectivamente hoy en día está en otra situación (Fernández, 2013: entrevista).

Generar un estatus al cronista, que se reconozca aún más su trabajo, ha desarrollado iniciativas que han permitido despertar un mayor interés. Por ejemplo, la creación de premios como el Nuevas Plumas, que ha recibido cientos de crónicas inéditas en cada una de sus ediciones. Para Juan Pablo Meneses, citado por Leila Guerriero, "ahí está el auge. El financiamiento, el sitio donde publicarlas, el pago, puede ser un fracaso, pero no tiene que ver con la esencia de contar una historia real, sino con la parte administrativa (Guerriero, 2012: s.p.).

Muchos periodistas jóvenes también están creyendo en proyectos personales, aunque no tengan dónde publicarlos y nadie los financie. Quieren contar una historia y luchan por hacerlo, con recursos propios, dedicando su tiempo, y ese es uno de los verdaderos éxitos del auge en la crónica latinoamericana actual. Eso sí, para el salvadoreño Carlos Dada no es un fenómeno nuevo: "la crónica siempre estuvo ahí, creo que simplemente empezó a ser más observada, hay algunos ensayistas o críticos literarios como Pablo Rafael que insisten en que hoy la gran literatura se está haciendo en la no ficción" (Dada, 2013: entrevista).

En España hay casos muy llamativos de estudiosos que han abordado este fenómeno: Albert Chillón, Roberto Herscher, Domenico Chiape, María Angulo y Jordi Carrión. Carrión, que ve una gran vitalidad en la crónica latinoamericana, fue el compilador de la antología Mejor que ficción, publicada por la editorial Alfaguara, y así ofrece su opinión:

Veo que el panorama es rico, variado, interesante, con frentes de renovación (multimedia, transmedia, periodismo en cómic, periodismo de datos) y frentes de continuidad (nuevo periodismo y periodismo clásico). La muerte de García Márquez ha impulsado el reconocimiento de la fundación de Nuevo Periodismo Iberoamericano como su gran heredera en la defensa de la crónica literaria. Al mismo tiempo, la Fundación Tomás Eloy Martínez, Martín Caparrós y Anguita lanzaban el premio La Voluntad de crónica en Argentina. Síntomas de que todo se mueve y avanza. Aunque el cierre de Orsai, por ejemplo, sea negativo, ha nacido El Estado Mental (Carrión, 2014: entrevista).

El caso mexicano es muy particular. Hace unos años sólo algunos autores dominaban la escena de la crónica; pero el tema de la violencia producida por el narcotráfico ha hecho visibles a una gran cantidad de cronistas mexicanos que dan cuenta de los horrores y las diferentes situaciones a las que se enfrentan:

Editorialmente hay más libros de crónicas y las editoriales buscan que los periodistas escriban cosas que antes no ocurrían, ahora es como una tendencia, una 
moda y las editoriales están buscando a periodistas que hagan trabajos rápidos sobre la coyuntura y mucho con la clave narrativa (Turati, 2013: entrevista).

Para el cronista mexicano Alejandro Almazán ha sido importante el trabajo de algunas revistas y, sobre todo, la férrea determinación de algunos cronistas que incluso arriesgan su vida. Otro aspecto importante es que los periódicos se dieron cuenta de que tenían que ser más críticos, que debían contar historias que permitieran entender de forma completa lo que estaba sucediendo:

Yo creo que más bien lo que ocurrió es que los periódicos se dieron cuenta que estaban llenos de notas, de gráficos y que informaban nada, no comentaban nada. En México al menos sí se dieron cuenta de eso y empezaron a abrir el abanico a las crónicas. Unas bien hechas, otras mal hechas, pero abrieron el abanico (Almazán, 2013: entrevista).

Si la crónica latinoamericana se ha extendido en los últimos años y ha tenido una mayor difusión, si se han creado redes y el trabajo de los cronistas es cada vez más conocido, en buena medida se debe a internet. Con una industria editorial todavía poco desarrollada, con unos canales de distribución de libros y revistas mediocres, la red se ha convertido en la mejor manera de acercar países, autores y lectores. Además, la creación de un buen número de medios digitales ha fortalecido la vitalidad de la crónica. Algunos han naufragado en el camino, pero quedan otros, que son testigos participantes del desarrollo de la crónica latinoamericana actual. El asunto se hace más importante cuando las diferentes iniciativas tienen otras formas de hacer llegar la información y se usan los recursos multimedia para hacerla más completa. Para el cronista peruano Marco Avilés, uno de los hechos que ha provocado el Boom es el fácil acceso de los textos en internet:

No creo que antes no hubiera cronistas, pero el impulso de internet, además de las revistas, ayuda a que todos estos cronistas que existían en sus diferentes países se volvieran una gran comunidad donde todos empezaron a leerse, más allá de las fronteras. Es un Boom que tiene que ver con que se está leyendo bastante en internet y no es un fenómeno económico, todo lo que se lee en internet es gratis (Avilés, 2013: entrevista).

Antes, los cronistas tenían que pedirle a conocidos en otros países que les enviaran una fotocopia de un libro o de una crónica, que los transmitieran por correo certificado o a través de un fax. Internet permitió tener acceso inmediato a contenidos que se publican en la red, incluso surgieron revistas digitales de crónica, así como blogs que se encargan de reproducir crónicas de diferentes autores. El editor colombiano Camilo Jiménez piensa que hay todo un ecosistema favorable para la crónica:

La crónica es un género que también reclama que los cronistas estén escribiendo, estén reflexionando sobre su oficio, estén tratando de desentrañar lo que hacen, como es un género tan volátil, es un género amplio, que podría compararse con el 
género de la novela porque caben todos los discursos en la crónica [...] Entonces hay un ecosistema favorable para que se hable de la crónica, para que se creen premios de crónica, para que se publiquen libros de crónica. Hablar de un Boom es un poco exagerado pero sí hay un ambiente favorable a la crónica. (Jiménez, 2013: entrevista).

Además de España, también hay estudiosos de la crónica y su renacimiento en Argentina, en Chile, en Ecuador, en México... En Colombia aparecen nombres como los de: Donaldo Alonso Donado Viloria, Daniel Samper Pizano, Maryluz Va1lejo, Juan José Hoyos o Carlos Mario Correa. Este último ve una serie de hechos que hacen que la crónica actual tenga una especial vitalidad:

Hay más estudiosos, hay trabajos de tipo doctoral. Se ha procurado que tenga un estatus literario, hay más defensores de la crónica latinoamericana, inclusive desde la academia, hay mayor aceptación de los lectores de este tipo de trabajos y eso se nota en que a los libros de crónica. Se han abierto concursos y las editoriales publican más libros de los cronistas, antologías y como solistas [...] Ha ganado terreno en el competido mundo de la literatura, en el competido mundo editorial; pero no hay un Boom porque hacer crónicas es muy costoso para los cronistas que lo hacen a título personal (Correa, 2014: entrevista).

Algunos estudiosos, como el ecuatoriano Jeovanny Benavides, cuestionanla denominación de Boom a lo que sucede con la crónica actual. Él, además, como cronista, ha vivido en carne propia las dificultades que supone escribir crónicas. Eso sí reconoce unas condiciones que han enriquecido lo que sucede con este tipo de textos:

Yo no lo vería como un Boom, sino como un auge no solo de la crónica sino del periodismo literario en general. Este auge (discreto) ha sido propiciado e impulsado desde algunos sectores editoriales, que precisamente quieren llamarlo Boom porque eso genera un impacto comercial (Benavides, 2014: entrevista).

Otros, como el cronista chileno Juan Pablo Meneses, son más suspicaces y piensan que el término ha sido usado de forma despectiva desde la academia y desde la literatura; pero la mención constante ha logrado que tome fuerza:

Cada vez veo más autores de ficción, cada vez veo más revistas literarias, que hablan tanto en contra del Boom de la crónica, que están haciendo un Boom realmente y a mí no me gusta la palabra Boom porque quiere decir que es sólo de una generación, a mí me gustaría que la crónica durara más tiempo, me parece claramente que es el género que mejor puede servir a Latinoamérica (Meneses, 2013: entrevista).

Hay quienes, sin embargo, son más escépticos, ven las difíciles condiciones que tienen los cronistas para poder publicar sus trabajos y para poder sobrevivir y no creen en la existencia de un Boom, como es el caso del editor argentino Diego Fonseca: 
No creo en la idea del Boom, pues requiere condiciones económicas de sostenibilidad que no se dan siempre - no todos los medios pagan bien, muchos pagan tarde, otros no pagan, el valor que se paga por cada texto no es ni cercanamente proporcional al tiempo y esfuerzos invertidos (Fonseca, 2014: entrevista).

Y también están los que son más radicales, los que piensan que lo de la crónica es simplemente un sueño, un anhelo de lo que algunos querrían que sucediera. Para la editora chilena Andrea Palet es arbitrario hablar de Boom en la crónica latinoamericana sin hacer un rastreo en otras culturas:

primero habría que despejar si hay un Boom de la crónica asiática, si hay un Boom de la crónica europea o africana, nadie ha dicho que no lo haya por lo tanto el término científico no sabemos si hay un Boom de la crónica latinoamericana en oposición a otras crónicas de otros continentes, puede que haya y no nos hayamos (Palet, 2014: entrevista).

Hay autores con una posición incluso burlona cuando se habla de la palabra Boom, frente a lo que han tenido que vivir, les parece ridículo que se plantee un término con un peso y una sonoridad tan rimbombante, en ese grupo se encuentra el escritor y periodista argentino Daniel Riera:

No, es una pavada lo del Boom, si fuera un Boom, habría pasado a buscarte en limosina y te hubiera dicho, por qué no vamos a pasar el día en Uruguay y charlamos tranquilos, no existe [...] es una cosa como de marketing, engañosa, no hay medios dispuestos a invertir en el trabajo de un cronista. El trabajo del cronista vale, si hubiera un Boom, habría una industria y no la hay [...] y no hay tantos lectores tampoco, son construcciones que forman parte de un micro mundo en el cual nos movemos en el que creemos que las cosas que nos importan a nosotros le importan a todo el mundo (Riera, 2013: entrevista).

\section{Conclusiones}

En América Latina siempre se ha buscado a una generación de escritores que logre volver a poner en lo más alto a las letras del continente. Hasta ahora sólo ha habido fracasos. Ninguna generación ha estado a la altura en calidad y en industria editorial de los miembros del Boom de la literatura latinoamericana.

Los más optimistas dicen que existe un nuevo Boom y que ese Boom no está en la literatura de ficción. Afirman que quienes mejor están contando los destinos del continente, quienes están produciendo textos más vitales, son los cronistas que han logrado desarrollar una obra significativa en los diferentes países de América Latina.

Dos de las grandes diferencias entre los miembros del Boom de la literatura latinoamericana y los cronistas actuales son el reconocimiento y la economía. La crónica no ha generado un fenómeno económico ni mediático como el que supuso la literatura latinoamericana del Boom. 
Existe un mayor interés en la crónica Latinoamérica, se habla más de ella. En Europa se han publicado antologías, artículos, se han organizado congresos, charlas, seminarios, algunos autores tienen columnas permanentes en diferentes periódicos. Diversas razones han ayudado a esta circunstancia: la creación de la Fundación Nuevo Periodismo Iberoamericano, la difusión que ha permitido internet, el desarrollo de revistas, el trabajo de editoriales comerciales, independientes y universitarias; el entusiasmo de autores consagrados que incluso han entendido que no necesitan hacer ficción para ganar un prestigio, el trabajo de jóvenes entusiastas que han convertido a las crónicas en sus proyectos de vida, etc.

Algunos cronistas venden bien sus libros, son capaces de llenar auditorios e incluso generan el interés en estudiosos para analizar su obra. Pero son casos aislados y no se puede hablar de un fenómeno general; aun así vale la pena analizar las razones expuestas y que justifican que en este momento haya un mayor interés en la crónica latinoamericana actual.

\section{Referencias bibliográficas}

Angulo, María (2014): Crónica y mirada. Madrid, Libros del K.O.

Benavides, Jeovanny (2014): Juan Villoro, el maestro de la dispersión total. Revista Sole.

Disponible en: http://www.revistasole.com/2014/10/juan-villoro-el-maestro-de-la.html. [Consulta: 20 de octubre de 2014]

Caparrós, Martín (2007): Por la crónica. Disponible en:

http://congresosdelalengua.es/cartagena/ponencias/seccion_1/13/caparros_martin.htm. [Consulta: 15 de febrero de 2012]

Carrión, Jordi (2012): Mejor que ficción. Crónicas ejemplares. Barcelona, Anagrama.

Chiape, Domenico (2010): Tan real como la ficción. Barcelona, Laertes.

Chillón, Albert (1999): Literatura y periodismo. Una tradición de relaciones promiscuas. Barcelona, Universitat Autónoma de Barcelona.

Chillón, Albert (2014): Literatura facticia. Literatura periodismo y comunicación. Barcelona, Universitat Autónoma de Barcelona.

Correa, Carlos (2011): La crónica reina sin corona. Medellín, EAFIT.

Donado, Donaldo (2003): Crónica anacrónica. Un estudio sobre el surgimiento, auge y decadencia de la crónica periodística en Colombia. Bogotá, Editorial Panamericana.

Ethel, Carolina (2008): La invención de la realidad. En: Babelia, núm. 868, El Pais, 12 de julio de 2008.

Faverón, Gustavo (2013): Breve historia de la explosión más larga del mundo. En: Buen Salvaje. Disponible en: http://buensalvaje.com/2013/01/09/big-bang-Boom/. [Consulta: 22 de octubre de 2014]

Guerriero, Leila (2012): "La verdad y el estilo". Reportaje publicado en El País, sección Cultura, 18 de febrero de 2012 El País. Disponible en: http://cultura.elpais.com/ cultura/2012/02/15/actualidad/1329307919_560267.html. [Consulta: 18 de febrero de 2012]

Jaramillo, Darío (2011): Antología de la crónica latinoamericana actual. Madrid, Alfaguara. Lobo, Ramón (2013): "Leila Guerriero: «El periodismo objetivo es la gran mentira del universo, todo es subjetivo»". En Jotdown. Disponible en: http://www.jotdown. es/2013/11/lei\%C2\%ADla-gue\%C2\%ADrrie\%C2\%ADro-el-periodismo-objetivo-es-lagran-mentira-del-universo-todo-es-subjetivo/. [Consulta: 2 de octubre de 2014] 
Muñoz, Boris (2011): Notas desabotonadas. La crónica latinoamericana. En: Antología de la crónica latinoamericana actual. Madrid, Alfaguara.

Puerta, Andrés (2012): El periodismo narrativo. La mejor forma de dejar huella de una sociedad en una época. Madrid, Editorial Académica Española.

Tarifeño, Leonardo (2012): "Periodismo narrativo: El nuevo Boom latinoamericano". La Nación, sección ADN Cultura, 10 de agosto de 2012. Disponible en: http://www.lanacion.com. ar/1497165-periodismo-narrativo-el-nuevo-Boom-latinoamericano. [Consulta: 18 de octubre de 2014]

Villarreal, Rogelio (2013): "La crónica es el gran retrato de nuestro tiempo". Revista Mexicana de Comunicación. Redacción, 28 de octubre de 2013. Disponible en: http://mexicanadecomunicacion.com.mx/rmc/2013/10/28/la-cronica-es-el-gran-retratode-nuestro-tiempo-rogelio-villarreal/. [Consulta: abril de 2014].

\section{Entrevistas}

Almazán, Alejandro (2013): Entrevista realizada en Medellín, Colombia, en noviembre de 2013.

Avilés, Marco (2013): Entrevista realizada en Lima, Perú, en octubre de 2013.

Benavides, Jeovanny (2014): Entrevista realizada por correo electrónico en marzo de 2014. Cantú, Elda (2013): Entrevista realizada en Lima, Perú, en octubre de 2013.

Carrión, Jordi (2014): Entrevista realizada por correo electrónico, en marzo de 2014.

Chillón, Albert (2014): Entrevista realizada por correo electrónico en abril de 2014.

Correa, Carlos (2014): Entrevista realizada en Medellín, Colombia, en noviembre de 2014.

Fernández, Patricio (2013): Entrevista realizada en Medellín, Colombia, en noviembre de 2013.

Fonseca, Diego (2014): Entrevista realizada por correo electrónico en marzo de 2014.

Jiménez, Camilo (2013): Entrevista realizada en Bogotá, Colombia, en diciembre de 2013.

Jursich, Mario (2013): Entrevista realizada en Bogotá, Colombia, en diciembre de 2013

Lafuente, Sandra (2014): Entrevista realizada por correo electrónico en mayo de 2014.

León, José (2013): Entrevista realizada en Guayaquil, Ecuador, en septiembre de 2013.

Meneses, Juan (2013): Entrevista realizada en Santiago de Chile, en septiembre de 2013.

Muñoz, Boris (2013): Entrevista realizada en Medellín, Colombia, en noviembre de 2013.

Palet, Andrea (2013): Entrevista realizada en Bogotá, Colombia, en diciembre de 2013.

Riera, Daniel (2013): Entrevista realizada en Buenos Aires, Argentina mayo de 2013.

Turati, Marcela (2013): Entrevista realizada en Medellín, Colombia, en noviembre de 2013.

Andrés Alexander Puerta Molina es Profesor de tiempo completo de la Universidad de Medellín (Colombia). Es comunicador social, periodista de radio, prensa y televisión, editor y corrector de estilo. magíster en Literatura Colombiana, doctor en Lenguajes y Manifestaciones Artísticas y Literarias. Investigador en las áreas de periodismo, literatura y redacción de textos. Autor del libro: El periodismo narrativo, la mejor manera de dejar huella de una sociedad en una época, de capítulos de libros y de artículos en revistas nacionales e internacionales. Finalista del premio Nuevas Plumas de Periodismo. Becario Colciencias para estudios doctorales a nivel nacional e internacional. Ganador Beca de Creación, en la modalidad de Crónica, del Museo Casa de la Memoria de Medellín. 